\title{
Review \\ Bench-to-bedside review: Mitochondrial injury, oxidative stress and apoptosis - there is nothing more practical than a good theory
} Hülya Bayır ${ }^{1,2}$ and Valerian E Kagan ${ }^{2}$

\author{
${ }^{1}$ Safar Center for Resuscitation Research, Department of Critical Care Medicine, School of Medicine, University of Pittsburgh, PA, USA \\ ${ }^{2}$ Center for Free Radical and Antioxidant Health, Department of Environmental and Occupational Health, School of Public Health, \\ University of Pittsburgh, PA, USA
}

Corresponding authors: Hülya Bayır, bayihx@ccm.upmc.edu. Valerian E Kagan, vkagan@eoh.pitt.edu

\begin{abstract}
Apoptosis contributes to cell death in common intensive care unit disorders such as traumatic brain injury and sepsis. Recent evidence suggests that this form of cell death is both clinically relevant and a potential therapeutic target in critical illness. Mitochondrial reactive oxygen species (ROS) have become a target for drug discovery in recent years since their production is characteristic of early stages of apoptosis. Among many antioxidant agents, stable nitroxide radicals targeted to mitochondria have attracted attention due to their ability to combine electron and free radical scavenging action with recycling capacities. Specific mechanisms of enhanced ROS generation in mitochondria and their translation into apoptotic signals are not well understood. This review focuses on several contemporary aspects of oxidative stress-mediated mitochondrial injury, particularly as they relate to oxidation of lipids and their specific signaling roles in apoptosis and phagocytosis of apoptotic cells.
\end{abstract}

The recent realization that mitochondria are at the intersection of the life and death of a cell, particularly through the involvement of mitochondrial damage in a range of diseases, has made them a promising target for drug discovery and therapeutic interventions [1]. Several types of critical illnesses are associated with cell death, both necrotic and apoptotic. The significant contributions of apoptotic pathways in cell death and to the pathogenesis of common intensive care unit (ICU) disorders, such as traumatic brain injury, acute respiratory distress syndrome, and sepsis, are well appreciated [2-4]. Because apoptosis usually includes mitochondrial injury, production of reactive oxygen species (ROS) and oxidative stress, this review is focused on apoptotic mechanisms through which oxidative stress realizes its signaling functions. This review is not a comprehensive analysis of available literature on this subject but rather is focused on several contemporary aspects of oxidative stress- mediated mitochondrial injury, particularly as they relate to oxidation of lipids and their specific signaling roles in apoptosis.

\section{Apoptosis}

Apoptosis, or programmed cell death, is a series of well coordinated and strictly controlled processes in which ligand binding to specific (death) receptors or cytotoxic insults result in the activation of several proteases and other hydrolytic enzymes, leading to proteolysis, DNA fragmentation and chromatin condensation [5]. Programmed cell death can be executed via extrinsic and intrinsic pathways depending on the stimulus leading to apoptosis (Figure 1). Extrinsic signals (such as cytokines, tumor necrosis factor (TNF)- $\alpha$, Fas ligand, glucocorticoids) bind to their receptors and trigger intracellular signaling leading to caspase-8 activation [6]. The TNF and Fas ligand pathways can induce both apoptosis and cell survival depending on the intracellular signaling pathways that are induced by them, and the balance seems to be related to activation of nuclear factor- $\kappa B$ [6].

In the intrinsic apoptotic pathway, pro-apoptotic signals (such as the pro-papototic Bcl-2 family proteins Bax and Bak) translocate to mitochondria, resulting in mitochondrial membrane permeabilization. This in turn provides a route for release of intermembrane space proteins (such as cytochrome c, apoptosis inducing factor (AIF), Endo G and Smac/DIABLO (Second mitochondria-derived activator of caspase/direct IAP binding protein with a low pl)) into the cytosol. Once in the cytosol, cytochrome c promotes the formation of the 'apoptosome', a molecular platform for the activation of caspase-9. The apoptosome also includes the

$\Delta \psi=$ mitochondrial transmembrane potential; 4-AT = 4-amino TEMPO; AIF = apoptosis inducing factor; APLT = aminophospholipid translocase; $\mathrm{CL}=$ cardiolipin; CLox = oxidized cardiolipin; IAP = inhibitor of apoptosis protein; ICU = intensive care unit; NO = nitric oxide; NOS = nitric oxide synthase; PS = phosphatidylserine; ROS = reactive oxygen species; SOD = superoxide dismutase; TEMPOL $=4$-hydroxy-2,2,6,6-tetramethyl piperidine-1-oxyl; TNF $=$ tumor necrosis factor. 


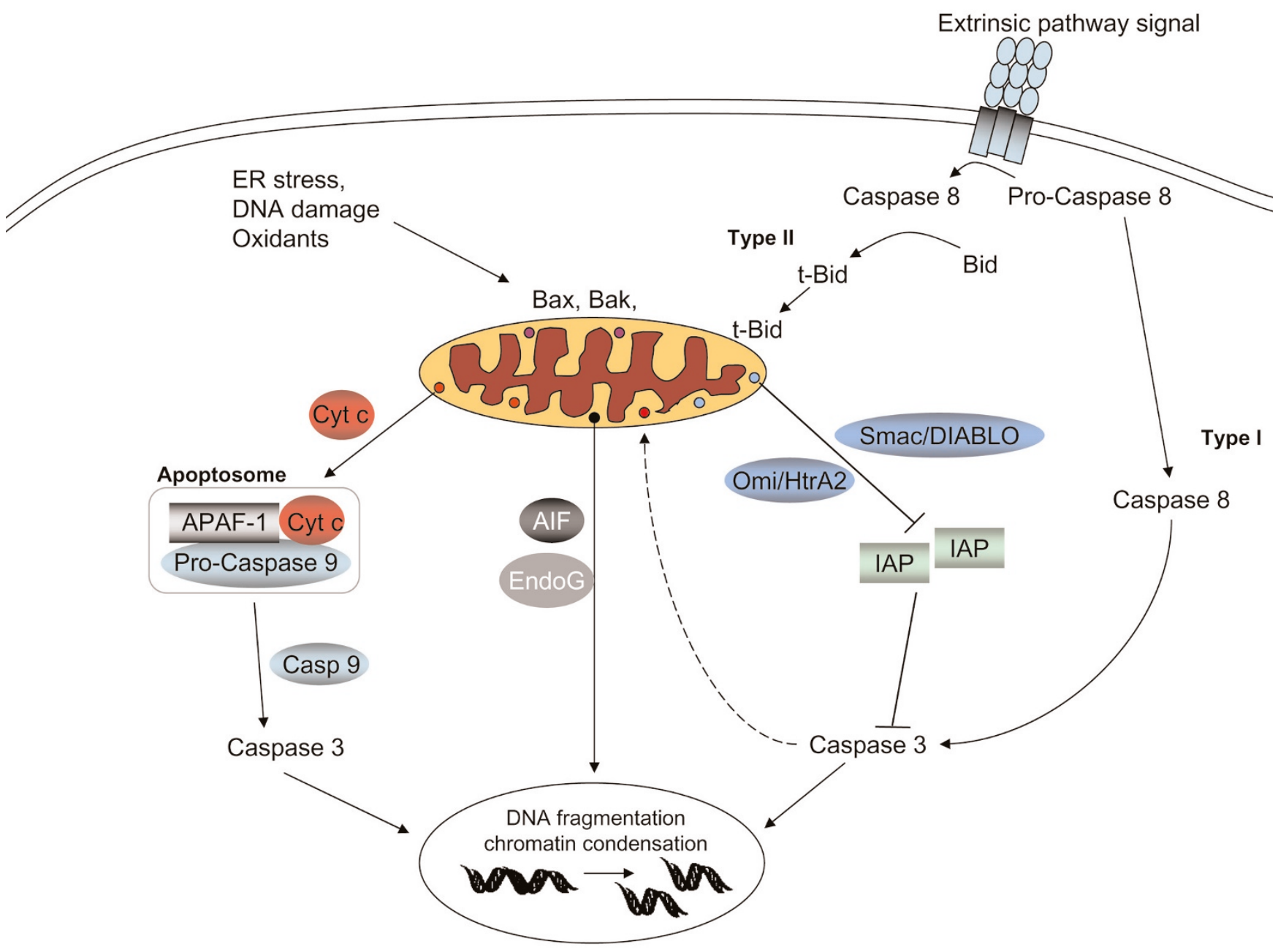

Programmed cell death can be executed via extrinsic and intrinsic pathways depending on the stimulus leading to apoptosis. In the intrinsic apoptotic pathway, pro-apoptotic signals (such as pro-apoptotic Bcl-2 family proteins Bax and Bak) translocate to mitochondria, resulting in mitochondrial membrane permeabilization. This in turn provides a route for release of intermembrane space proteins (such as cytochrome $\mathrm{c}$ (Cyt $\mathrm{c}$ ), apoptosis inducing factor (AIF), Endo G and Smac/DIABLO (Second mitochondria-derived activator of caspase/direct inhibitor of apoptosis protein binding protein with a low pl)) into the cytosol. Once in the cytosol, cytochrome c promotes the formation of the 'apoptosome', a molecular platform for the activation of caspase-9. In turn, active caspase-9 catalyzes the proteolytic activation of caspase-3. This leads to DNA fragmentation and chromatin condensation. Caspase 3 may also serve to amplify the initial death signal by helping to promote further cytochrome $\mathrm{c}$ release from mitochondria. Smac/DIABLO and Omi stress-regulated endoprotease/high temperature requirement protein A2 (Omi/HtrA2) promote apoptosis indirectly by binding to and antagonizing members of the inhibitor of apoptosis protein (IAP) family. AIF and Endo G, on the other hand, translocate from the cytosol to the nuclear compartment, leading to DNA fragmentation and chromatin condensation. Extrinsic signals bind to their receptors and trigger intracellular signaling, leading to caspase- 8 activation. Activation of caspase- 8 by extrinsic stimuli (such as tumor necrosis factor- $\alpha$, Fas ligand) involves mitochondria-dependent signaling (in type II cells) and results in cleavage of the pro-apoptotic Bcl-2 family protein Bid to t-Bid. Translocation of $\mathrm{t}$-Bid to the mitochondria is believed to be one of the signals for mitochondrial events during apoptosis. In type I cells, on the other hand, execution of apoptosis occurs without significant participation of mitochondria. APAF-1, apoptosis protease activating factor 1; ER, endoplasmic reticulum.

apoptosis protease activating factor 1 (APAF-1) and ATP/ dATP. In turn, active caspase- 9 catalyzes the proteolytic activation of the effector caspases. This leads to the expression of two key apoptotic phenotypes, namely, exposure of phosphatidylserine (PS) on the outer surface of plasma membrane and DNA fragmentation and degradation. Recent studies show that caspase 3 may also serve to amplify the initial death signal by helping to promote further cytochrome c release from mitochondria [7]. Smac/DIABLO promote apoptosis indirectly, by binding to and antagonizing members of the inhibitor of apoptosis protein (IAP) family. AIF and Endo $G$, on the other hand, translocate from the cytosol to the nuclear compartment, leading to DNA fragmentation and chromatin condensation $[5,8]$. 
The mechanisms by which the intermembrane space proteins are released from mitochondria remain controversial [9]. In general, two mechanisms have been described, the occurrence of either of which might depend on the nature of the apoptotic stimulus. In the first mechanism, a permeability transition pore opens in the inner membrane, allowing water and molecules up to $1.5 \mathrm{kDa}$ to pass through [10]. Although alternative models have been proposed [11], most models imply that the adenine nucleotide transporter in the inner membrane and the voltage dependent anion channel in the outer membrane are components of this pore [12]. Opening of the permeability transition pore leads to equilibration of ions across the inner mitochondrial membrane with loss of mitochondrial transmembrane potential $(\Delta \psi)$ and swelling of the matrix as water enters. The latter can result in sufficient swelling to break the outer membrane, resulting in the release of pro-apoptotic factors from the intermembrane space to the cytosol.

The second mechanism is mediated by $\mathrm{Bcl}-2$ family members acting directly on the outer mitochondrial membrane. In this process, oligomerization of pro-apoptotic Bcl-2 family members Bax and Bak plays an essential role in the permeabilization of the outer mitochondrial membrane [13]. We and others have shown that Bax/Bak translocation to mitochondria causes ROS generation and cardiolipin (CL) oxidation in the mitochondria [14-15]. In Bax/Bak double knock out cells, ROS production and $\mathrm{CL}$ oxidation are decreased. These cells, but not cells lacking only one of these proteins, have been found to be resistant to a variety of apoptotic stimuli, including oxidants, that act through the mitochondrial pathway [16]. Irrespective of its mechanisms, permeabilization of the mitochondrial outer membrane is considered a point of no return for programmed cell death because of the release of caspase activators such as cytochrome c.

Mitochondria appear to be involved in both the extrinsic and intrinsic apoptotic pathways. While the intrinsic apoptotic pathway is mitochondria dependent, cells undergoing programmed death via the extrinsic pathway can be classified as type I and II depending on whether the mitochondria is involved or not. In type I cells, execution of apoptosis occurs without significant participation of mitochondria. This kind of cell death mechanism may be important for developmental tissue remodeling [18]. In type II cells on the other hand, mitochondria are involved in the execution of apoptosis as a second loop. In some membrane death receptor-mediated systems, activation of caspase- 8 by extrinsic stimuli (such as TNF- $\alpha$ and Fas ligand) involves mitochondria-dependent signaling and results in cleavage of the pro-apototic Bcl-2 family protein Bid to $\mathrm{t}$-Bid. Translocation of $\mathrm{t}$-Bid to mitochondria is believed to be one of the signals triggering mitochondrial events during apoptosis [5].

\section{Mitochondrial energy production}

Mitochondria play a critical role in cellular energy production via electron transport chain-dependent synthesis of ATP.
Derangements in mitochondrial function mostly affect cells that have a high energy demand, such as neurons and cardiac myocytes. The mitochondrial electron transport chain is composed of five multimeric complexes [19]. Electron transport between complexes I to IV is coupled to extrusion of protons from complexes I, III and IV into intermembrane space, creating an electrochemical gradient $(\Delta \psi)$ across the inner mitochondrial membrane (Figure 2). This movement of electrons generates an alkaline matrix and an acidic intermembrane space. Protons then flow through complex $V$ (ATP synthase), which utilizes the energy to synthesize ATP from ADP [20].

Since molecular oxygen is the terminal electron acceptor in the mitochondrial electron transport chain, assessments of mitochondrial function are often performed through the measurement of oxygen consumption in isolated mitochondria. Intact mitochondria provided with inorganic phosphate and an oxidizable substrate (such as succinate) respire relatively slowly in the absence of ADP. Addition of ADP initiates a sudden burst of vigorous respiration and the ADP is rapidly phosphorylated to produce ATP. This is called coupled respiration: oxygen consumption is coupled to the production of ATP. When all the ADP is depleted, the respiration rate returns to its original level. The active rate in the presence of ADP is called 'state 3 respiration' and the slower rate when all the ADP has been phosphorylated is referred to as 'state 4 respiration'. State 4 respiration reflects the rate of leakage of proton back across the inner mitochondrial membrane into the matrix and is not coupled to complex $\mathrm{V}$ or ATP synthesis. The ratio of state 3 to state 4 is called the respiratory control index. This ratio varies with the substrate and the experimental details; in general, it is at least 5 or greater if the isolated mitochondria are in good condition. In state 3 respiration, control of respiration may involve several components, including the adenine nucleotide translocator and cytochrome c oxidase [20-24]. The extramitochondrial ATP/ADP ratio, extramitochondrial Pi concentration and the supply of hydrogen also play significant roles in controlling respiration [25]. Under disease conditions decreased state 3 respiration and increased state 4 respiration may be observed. Many compounds can inhibit mitochondrial respiration; the precise pattern of inhibition differs from one compound to the next. Important inhibitors are cyanide, antimycin, rotenone and oligomycin, all of which block different components of the electron transport chain (Figure 2). A small group of compounds called uncoupling agents cause unrestrained oxygen uptake in the absence of ADP. None of the energy released during this type of oxidation is captured; it is all dissipated as heat [26].

An important component of the electron transport chain, cytochrome $\mathrm{c}$ is located in the intermembrane space and shuttles electrons between mitochondrial complexes III and IV. In addition to this well known and essential function, cytochrome $\mathrm{c}$ plays a critical role in the activation of 


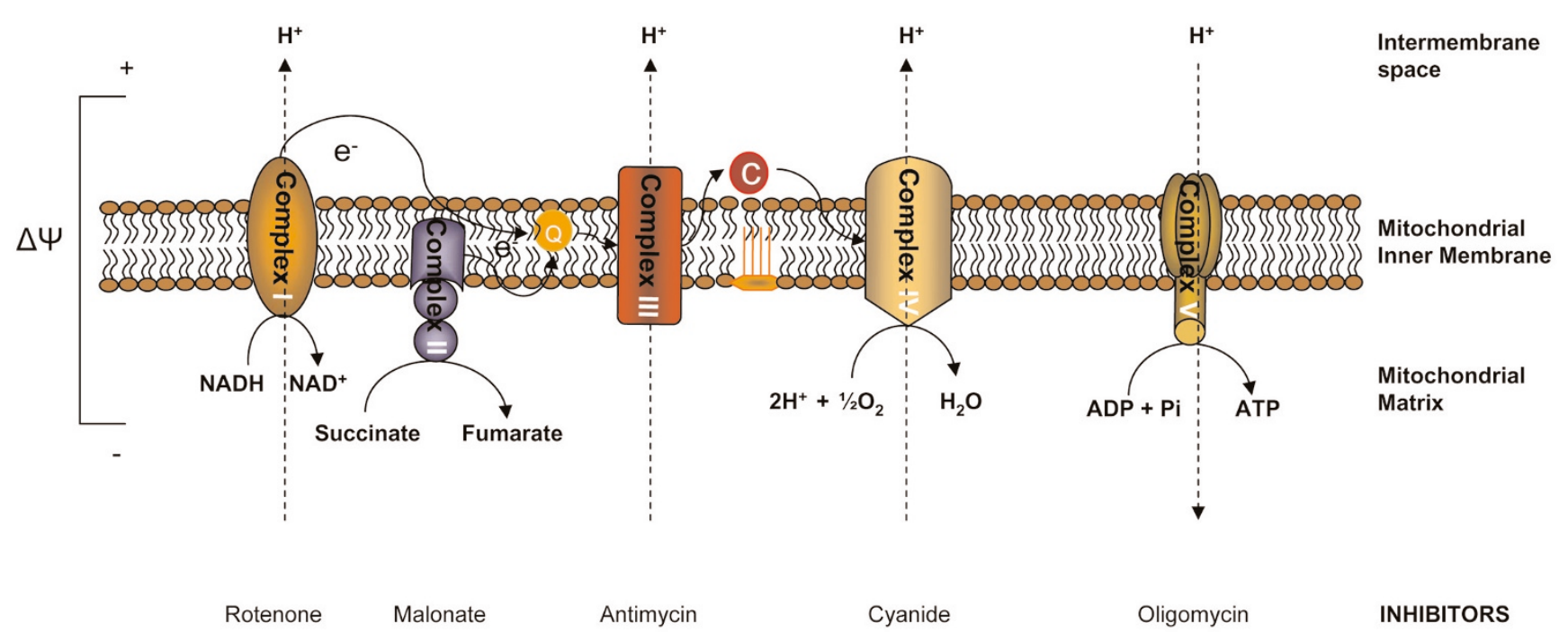

Mitochondrial energy production. The mitochondrial electron transport chain is composed of five multimeric complexes. Electron transport between complexes I to IV is coupled to extrusion of protons from complexes I, III and IV into the intermembrane space, creating an electrochemical gradient $(\Delta \psi)$ across the inner mitochondrial membrane. Protons then flow through complex V (ATP synthase), which utilizes the energy to synthesize ATP from ADP. Some common mitochondrial respiratory chain inhibitors are shown. C, cytochrome c; $\mathrm{Q}$, ubiquinone.

caspases during apoptosis [27]. Release of cytochrome c from mitochondria is one of the early stages of the apoptotic program, designating a point of no return in a cell's disintegration. It is also believed that the detachment of cytochrome $\mathrm{c}$ from the inner membrane and its release into the cytosol is one of the rate limiting events in the execution of the apoptotic program [28].

\section{Mitochondrial dysfunction in critical illness}

Mitochondrial dysfunction has been reported during critical illness in the ICU. We will briefly mention studies on sepsis and severe traumatic brain injury. The reader is referred to excellent reviews specifically describing mitochondrial dysfunction in these disease states [29-31]. Long term laboratory models of sepsis ( $>12$ hours) and sparse human data have shown decreases in mitochondrial activity or ATP concentrations [32-34]. In septic shock patients examined within 24 hours of ICU admission, the degree of skeletal muscle mitochondrial dysfunction was associated with the severity of the disease [32]. In this work, tissue ATP levels were significantly lower in non-survivors than in an orthopedic surgical control population, but they were maintained in those who survived sepsis. Complex I activity had a significant inverse correlation with norepinephrine requirements and nitrite/nitrate concentrations. The pathogenesis of mitochondrial dysfunction during sepsis is complex and multifactorial. Nitric oxide (NO), with its inhibitory effects on electron transport chain complexes, is believed to play an important role [29]. However, it has also been shown that low levels of NO stimulate mitochondrial proliferation, suggesting that effects of $\mathrm{NO}$ on mitochondrial function during sepsis depend on its concentration and the timing of its release [35]. An alternative idea suggested by some investigators is that mitochondrial dysfunction during sepsis may be due to an adaptive cellular strategy to reduce cellular energy expenditure, similar to hibernation [29].

Studies in traumatic brain injury also suggest derangements in mitochondrial function in experimental models and humans [30]. Mitochondrial dysfunction has been documented after both experimental and clinical head injury [30,36-39]. Studies in rodents suggest that alterations in mitochondrial function begin early and may persist for days following injury. A recent work evaluated the time course of cortical mitochondrial dysfunction in adult mice after experimental traumatic brain injury [40]. The results showed impairment in mitochondrial bioenergetics concomitant with accumulation of an oxidative stress marker, 4-hydroxynonenal, as an index of global lipid peroxidation. In addition, CL hydroperoxides have been identified as one of the major contributors to overall lipid peroxidation and mitochondrial dysfunction early after injury [41].

Growing interest has been focused on developing new therapeutic strategies able to combat mitochondrial dysfunction. Several pharmacological agents are currently under investigation, including novel antioxidants, uncoupling proteins and mitochondrial permeability transition pore inhibitors $[30,42]$. One of these agents, cyclosporine, a mitochondrial permeability transition pore inhibitor, has shown benefits in 
Figure 3

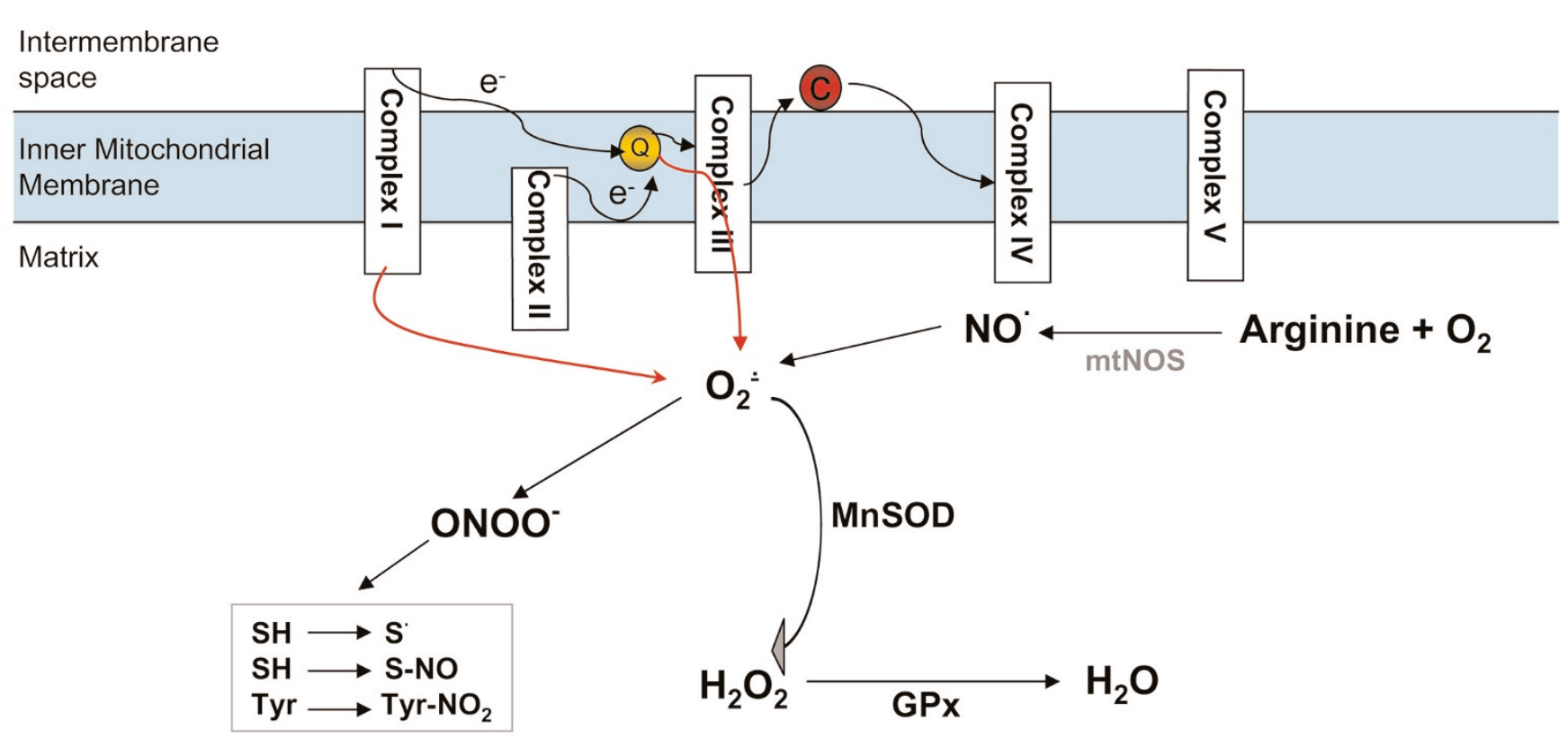

Mitochondrial oxidative stress. In the mitochondria, superoxide can be produced by respiratory complexes. Complex I in the brain and complex III in the heart and lung seem to be the primary sources of mitochondrial superoxide production. Superoxide is detoxified by manganese superoxide dismutase (MnSOD) to hydrogen peroxide $\left(\mathrm{H}_{2} \mathrm{O}_{2}\right)$ in the mitochondria. Glutathione peroxidases (GPxs) convert hydrogen peroxide to water. Nitric oxide (NO) generated from (mitochondrial) nitric oxide synthase (mt)NOS can compete with MnSOD and form peroxynitrite (ONOO-). Peroxynitrite in turn initiates thiol oxidation or nitrosylation and tyrosine nitration. $\mathrm{C}$, cytochrome $\mathrm{c}$; $\mathrm{O} 2$; superoxide; $\mathrm{Q}$, ubiquinone.

experimental traumatic brain injury models with improvement of mitochondrial function, cerebral metabolism and tissue damage $[43,44]$. The effect of cyclosporin on immune function and outcome is currently under investigation in clinical traumatic brain injury [45].

\section{Oxidative stress}

While small fluctuations in the steady-state concentrations of some free radicals may actually play a role in intracellular signaling in normal physiology [46], uncontrolled increases in the generation of free radicals exceed the capacity of antioxidant mechanisms to defend against them, resulting in oxidative stress with damage to lipids, proteins and DNA. Among the major biologically relevant free radical species in cells and biofluids are a one-electron product of oxygen reduction, the superoxide anion radical, and its dismutation product, hydrogen peroxide $\left(\mathrm{H}_{2} \mathrm{O}_{2}\right)$. The latter can be further reduced to a highly potent oxidant, the hydroxyl radical; alternatively, hydrogen peroxide can be activated by hemeperoxidases to reactive (oxoferryl) intermediates, which are also very potent oxidants [47]. Up to $1 \%$ of all oxygen consumption is estimated to form superoxide [5]. In the mitochondria, superoxide can be produced by respiratory complexes and individual enzymes on the outer mitochondrial membrane, on both sides of the inner mitochondrial membrane and in the matrix [48]. The relative contribution of each site to the overall superoxide production is tissue and respiratory state dependent. Complex $I$ in the brain [49] and complex III in the heart and lung [48,50] seem to be the primary sources of mitochondrial superoxide production under normal conditions. The rate of superoxide production increases with state 4 respiration (when the electron transport chain slows down and becomes more reduced) and in the presence of inhibitors [20]. When the electron transport chain is dysregulated or disrupted, particularly at the level of complexes I and/or III, the production and release of superoxide radicals increase (Figure 3) [51]. Outside of mitochondria, NADPH oxidases, particularly in polymorphonuclear neutrophils, macrophages and endothelial cells [52], xanthine oxidase [53] and cytochrome P450-dependent oxygenases [54] are the major sources of superoxide production.

A family of specialized enzymes, superoxide dismutases (SODs), convert superoxide to hydrogen peroxide, a relatively stable molecule [55]. Although the dismutation of superoxide to hydrogen peroxide can occur spontaneously, the role of SODs is to increase the rate of the reaction to that of a diffusion-controlled process. In the cytosol and the intermembrane space of mitochondria, superoxide is eliminated by $\mathrm{Cu}, \mathrm{Zn}-\mathrm{SOD}$, whereas in the matrix it is eliminated by MnSOD [48]. Glutathione peroxidase in turn reduces hydrogen peroxide to water and molecular oxygen by using glutathione [56]. 
Another important free radical species produced by cells is $\mathrm{NO}$, whose formation from arginine and oxygen is catalyzed by a family of $\mathrm{NO}$ synthases (NOSs). Although its presence, localization and physiological role are debated, a mitochondrial NOS isoform (mtNOS), possibly associated with the mitochondrial inner membrane, has recently been described $[57,58]$. NO can bind to heme groups of hemoproteins, including cytochrome oxidase. In the latter case, the important consequence is inhibition of respiration [59]. Chemically, NO is relatively inert. Similarly, superoxide itself is not particularly redox reactive. However, the toxic potential of both small radical species may be enhanced by their interaction, which leads to the production of a very potent oxidant, peroxynitrite (ONOO-) [60]. NO and peroxynitrite exert differential inhibitory effects on the mitochondrial electron transport chain. Reactions of peroxynitrite with respiratory complexes and cytochrome $\mathrm{c}$ lead to their inactivation via free radical mechanisms, including thiol oxidation or nitrosylation and tyrosine nitration [61].

\section{Mitochondrial ROS production and oxidative signaling in apoptosis}

Mitochondrial ROS production is one of the very early events preceding collapse of mitochondrial membrane potential, release of pro-apoptotic factors, and activation of caspases [8]. However, specific mechanisms of enhanced ROS generation in mitochondria and their translation into apoptotic signals are not well understood. Cytochrome c, the major player in post-mitochondrial caspase activation, was found to have yet another, earlier function during the mitochondrial stage of apoptosis. This role includes its interactions with a mitochondria-specific phospholipid, CL. The result of this interaction is a high affinity cytochrome c-CL complex which acts as a specific and potent oxidant. In the presence of hydrogen peroxide, this complex functions as a CL-specific oxygenase catalyzing the oxidation of $\mathrm{CL}$, which occurs early in apoptosis [62]. This has been established in a variety of cell lines undergoing apoptosis induced by pro-oxidant and non-oxidant pro-apoptotic agents in vitro. Our studies in experimental traumatic brain injury and hemorrhagic shock confirmed that this mechanism is also functional in vivo $[41,63]$. We have shown that selective oxidation of CL takes place during apoptosis while other, more abundant phospholipids (such phosphatidylcholine and phosphatidylethanolamine) remain non-oxidized in spite of the fact that they contain sufficient amounts of polyunsaturated fatty acid residues susceptible to oxidation [41].

The regulation of cytochrome c-CL interactions and the peroxidase function of the complex are not fully understood. However, several important details concerning this function of cytochrome $\mathrm{c}$ are beginning to emerge. For example, binding to $\mathrm{CL}$ turns off cytochrome c's function as an electron carrier but turns on its peroxidase activity [64]. Notably, oxidized CL (CLox) has a markedly lower affinity for cytochrome $\mathrm{c}$ and abandons the complex $[65,66]$. CL oxidation products (CLox; mostly cardiolipin hydroperoxides) accumulate in the mitochondria, leading to the release of pro-apoptotic factors into the cytosol (Figure 4). The specific mechanisms through which peroxidized $\mathrm{CL}$ induces a permeability transition in mitochondria and the subsequent release of pro-apoptotic factors need further analysis; however, this important task of CLox has been documented both in cells during apoptosis as well as isolated mitochondria [67]. It is essential, therefore, to understand the metabolic mechanisms involved in controlling CLox content in mitochondria. Interestingly, CL hydroperoxides are endogenous substrates for phospholipid-hydroperoxide glutathione peroxidase (Gpx IV) [68], and transgenic mice overexpressing this enzyme are protected against oxidative stress-induced apoptosis [69].

\section{Mitochondrial apoptosis as a target for drug discovery}

Because apoptosis contributes to disease processes in many critical illnesses, such as sepsis, trauma and acute respiratory distress syndrome [2-4], it is a clinically relevant mechanism that may represent a potential therapeutic target [70]. Mitochondrial ROS have become a target for drug discovery in recent years because their production is characteristic of early stages of apoptosis. Among many antioxidant agents, stable nitroxide radicals have attracted attention due to their ability to combine radical scavenging action with recycling capacities [71]. By accepting one electron, nitroxide radicals are converted to their respective hydroxylamines. These hydroxylamines act as effective ROS scavengers to produce nitroxides, that is, they undergo recycling [72]. Furthermore, nitroxide radicals possess SOD mimetic activity $[73,74]$. Although nitroxides (such as 4-hydroxy-2,2,6,6-tetramethyl piperidine-1-oxyl (TEMPOL)) have been extensively investigated as successful cytoprotectors in a number of experimental models of oxidative stress [75-79], the required high concentrations (millimolar) have limited in vivo applications of nitroxides [80].

Several recent studies indicate that targeting of nitroxides to mitochondria enhances their anti-apoptotic activity [81-84]. Dessolin and colleagues [81] have reported that accumulation of TEMPOL in mitochondria was substantially increased by conjugating it with a Salen-Mn(III) complex of o-vanillin (EUK-134), and the targeted nitroxide delayed apoptosis after an exogenous oxidative insult. Dhanasekaran and colleagues [82] have also demonstrated that a mitochondria-targeted conjugate of nitroxide with a positively charged triphenylphosphonium (mitocarboxy peroxyl) inhibited peroxide-induced oxidative damage and apoptosis. We have previously reported a significant increase in the cytoprotective effects of 4-amino TEMPO (4-AT) by coupling it to a segment of a membraneactive compound, gramicidin S [84]. Furthermore, the activity of the mitochondrially targeted electron acceptor conjugates of 4-AT with gramicidin S prolonged survival in rats subjected to lethal hemorrhagic shock even in the absence of resuscitation with asanguinous fluids or blood [63]. 


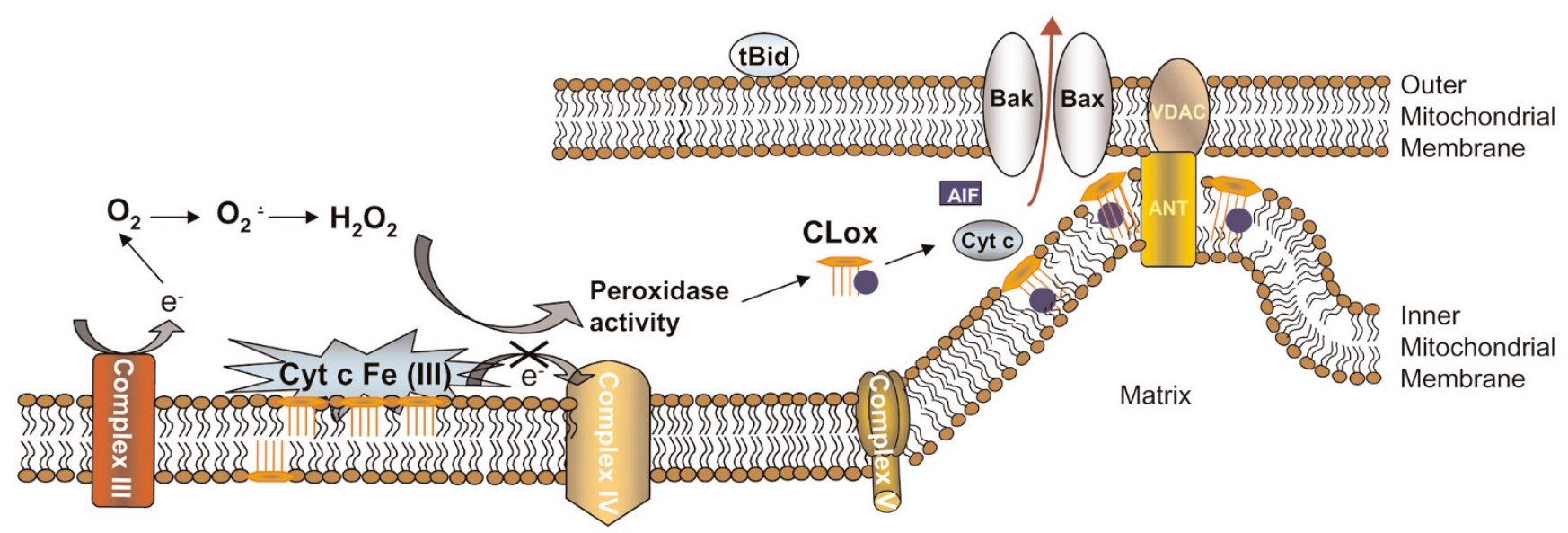

Mitochondrial reactive oxygen species production and oxidative signaling in apoptosis. Interactions of cytochrome c (Cyt c) with the mitochondria specific phospholipid cardiolipin (CL) result in a high affinity cytochrome C-CL complex that acts as a specific and potent oxidant. In the presence of hydrogen peroxide, this complex functions as a CL-specific oxygenase catalyzing oxidation of CL. Binding with CL turns off cytochrome C's function as an electron carrier but turns on its peroxidase activity. Oxidized CL has a markedly lower affinity for cytochrome $\mathrm{c}$ and abandons the complex. CL oxidation products (CLox; mostly cardiolipin hydroperoxides) accumulate in the mitochondria, leading to the release of pro-apoptotic factors into the cytosol (Figure 4). AIF, apoptosis inducing factor; ANT, adenine nucleotide translocase; VDAC, voltage-dependent anion-selective channel.

\section{Control of apoptosis and apoptotic clearance in critical illness}

During critical illness, a number of cell types in different tissues undergo apoptosis [6,70]. Excessive cell death, including apoptotic cell death, contributes to the pathogenesis of traumatic brain injury and organ failure in sepsis $[2,4]$. Paradoxically, insufficiency of cell death may also be associated with the pathogenesis of critical illnesses. An important example is delayed apoptosis and ineffective clearance of neutrophils, which is associated with multiple organ failure $[85,86]$. Neutrophil apoptosis and their effective clearance are particularly important in modulation of the inflammatory response [87]. Prolongation of neutrophil life span may have important implications in delayed resolution of inflammation. Therefore, timely elimination of excessive neutrophils via apoptotic pathways is imperative. Neutrophils are produced at a rate of 1 to $2 \times 10^{11}$ cells per day and they survive in the circulation for approximately 48 hours before undergoing apoptosis [88]. Neutrophils can undergo apoptosis via intrinsic and extrinsic pathways, the latter requiring mitochondrial amplification [89]. The role played by mitochondria in the regulation of cell life span is perhaps most crucial in neutrophils compared to other cell types in the body [90]. Mature neutrophils contain few mitochondria, although the amount of these apoptosis 'orchestrating' organelles is sufficient to trigger and execute common pathways of apoptosis and to express the signals essential for the effective clearance of them $[89,91]$.

Macrophage recognition and uptake of apoptotic cells (also termed 'efferocytosis') is an important cell-cell interaction regulating inflammation $[92,93]$. This interaction triggers not only effective clearance of apoptotic cells but also causes suppression of the inflammatory response, thus limiting the local tissue response and normally leading to quiet cell removal [94-96]. In contrast, inefficient apoptotic cell clearance is pro-inflammatory and immunogenic [97]. The recognition of different types of apoptotic cells, including neutrophils, by macrophages is largely dependent on the appearance on the cell surface of an anionic phospholipid, PS, which is normally confined to the cytosolic leaflet of the plasma membrane [98]. Thus, externalization of PS during apoptosis generates an 'eat-me' signal for macrophages $[94,99]$. Development and utilization of non-toxic molecules regulating apoptosis, and particularly phagocytosis of neutrophils, may provide a novel therapeutic strategy. Notably, asymmetric distribution of PS across the plasma membrane is mainly due to the activity of a specialized enzymatic mechanism, aminophospholipid translocase, APLT [98]. The enzyme contains redox-sensitive thiol groups and its inhibition by oxidative/nitrosative stress results in PS externalization (Figure 5) [100]. This suggests that nitrosylation of sensitive cysteine residues in APLT may be a promising strategy to research in the drug discovery programs aimed at regulating inflammatory responses. Indeed, our experiments with neutrophil-like $\mathrm{HL}-60$ cells demonstrated that S-nitrosylation of critical cysteine residues in APLT using a cell-permeable transnitrosylating agent, S-nitroso-acetyl-cysteine, resulted in egression of PS, rendering these cells recognizable by macrophages [100]. This approach represents a new strategy in regulating the life-span of neutrophils and their clearance by macrophages. Further development of the strategy for 


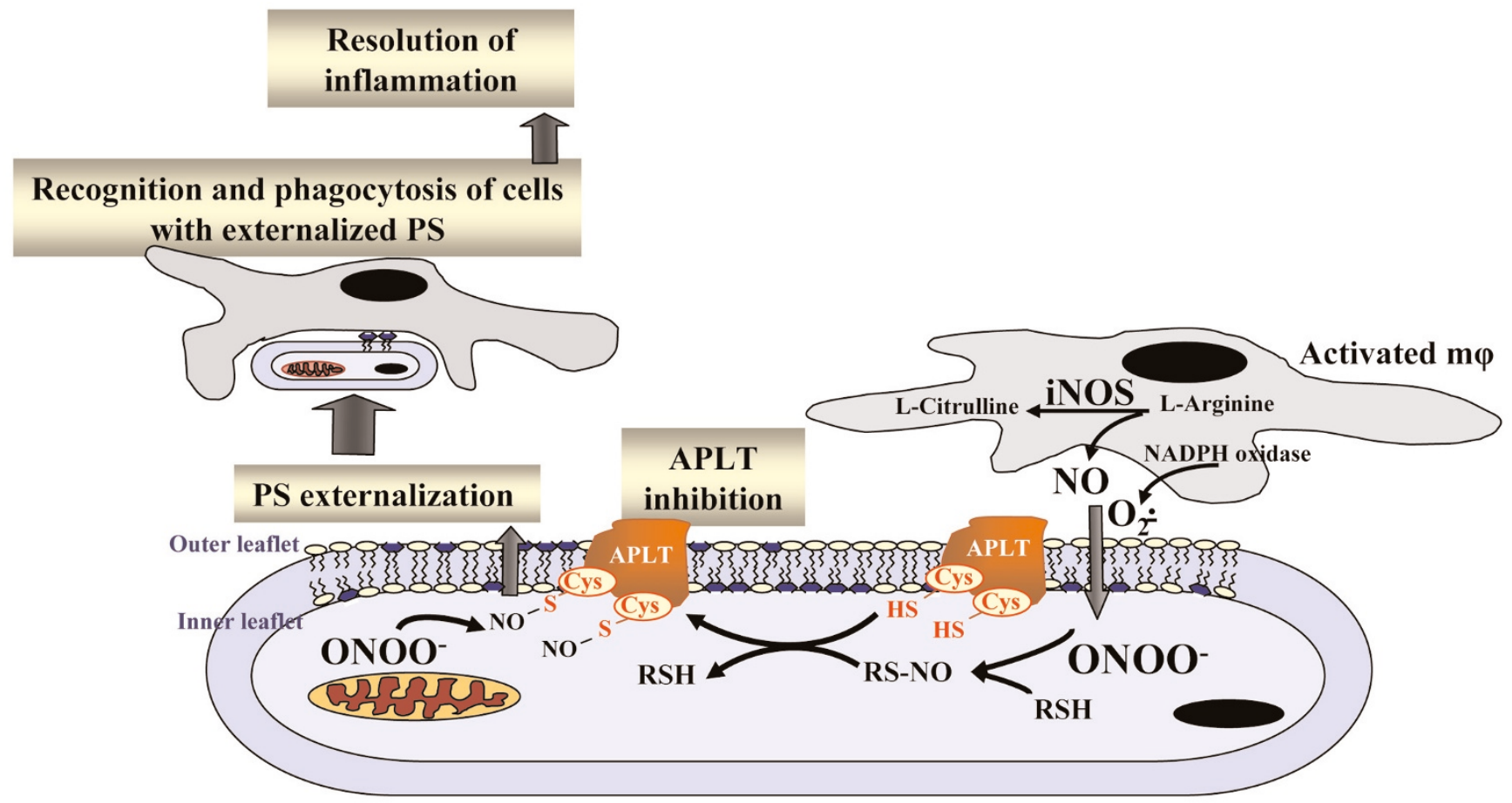

The recognition of apoptotic neutrophils by macrophages is largely dependent on the appearance on the cell surface of an anionic phospholipid, phosphatidylserine (PS), which is normally confined to the cytosolic leaflet of the plasma membrane. Asymmetric distribution of PS across the plasma membrane is mainly due to the activity of a specialized enzymatic mechanism, aminophospholipid translocase (APLT). S-nitrosylation of critical cysteine residues in APLT results in its inhibition, leading to PS externalization. This in turn triggers not only effective clearance of apoptotic cells but also causes suppression of inflammatory response. iNOS, inducible nitric oxide synthase; NO, nitric oxide.

expedited clearance of neutrophils in vivo may be useful in overcoming the consequences of insufficient and delayed elimination of neutrophils causing dysregulation and exacerbation of inflammatory responses. It is tempting to speculate that the delivery of reagents required for transnitrosylation of target cysteine residues in APLT may be achieved using novel nanoparticle-based vectors [101]. Lately, carbon nanotubes have demonstrated significant potential in the targeted delivery of their cargoes to accomplish temporally and spatially predetermined release of specific regulators and inhibitors [102,103]. While these strategies may look futuristic, recent exponential development of nanotechnologies promises that these plans are not overly optimistic.

\section{Conclusion}

In this review, we briefly considered several theoretical issues relevant to the role that mitochondria play in oxidative stress, oxidative signaling and the regulation of apoptosis. It is true that translation of these theoretical considerations into practical predictors of outcomes, biomarkers and new effective drugs in critical illnesses may take some time. However, we are encouraged by the previous experiences of many successful researchers in the field of drug discovery who proved that 'there is nothing more practical than a good theory'.

\section{This article is part of a review series on Translational research, edited by John Kellum.}

Other articles in the series can be found online at http://ccforum.com/articles/ theme-series.asp?series=CC_Trans

\section{Competing interests}

The authors declare that they have no competing interests.

\section{Acknowledgements}

Supported by grants from American Heart Association $0535365 \mathrm{~N}$, Laerdal Foundation and NIH (U19A1068021, HD057587), US Army Medical Research and Materiel Command/Telemedicine and Advanced Technology Research Center (DAMD 17-01-2-0038).

\section{References}

1. Anders MW, Robotham JL, Sheu SS: Mitochondria: new drug targets for oxidative stress-induced diseases. Expert Opin Drug Metab Toxicol 2006, 2(1):71-79.

2. Matute-Bello G, Martin TR: Science review: apoptosis in acute lung injury. Crit Care 2003, 7(5):355-358.

3. Wesche DE, Lomas-Neira JL, Perl M, Chung CS, Ayala A: Leukocyte apoptosis and its significance in sepsis and shock. $J$ Leukoc Biol 2005, 78(2):325-337. 
4. Zhang X, Chen Y, Jenkins LW, Kochanek PM, Clark RS: Benchto-bedside review: Apoptosis/programmed cell death triggered by traumatic brain injury. Crit Care 2005, 9(1):66-75.

5. Orrenius S, Gogvadze V, Zhivotovsky B: Mitochondrial oxidative stress: implications for cell death. Annu Rev Pharmacol Toxicol 2007, 47:143-183.

6. Oberholzer C, Oberholzer A, Clare-Salzler M, Moldawer LL: Apoptosis in sepsis: a new target for therapeutic exploration. Faseb J 2001, 15(6):879-892.

7. Lakhani SA, Masud A, Kuida K, Porter GA, Jr., Booth CJ, Mehal WZ, Inayat I, Flavell RA: Caspases 3 and 7: key mediators of mitochondrial events of apoptosis. Science 2006, 311(5762): 847-851.

8. Kroemer G Galluzzi L, Brenner C: Mitochondrial membrane permeabilization in cell death. Physio/ Rev 2007, 87(1):99-163.

9. Gogvadze V, Orrenius S, Zhivotovsky B: Multiple pathways of cytochrome c release from mitochondria in apoptosis. Biochim Biophys Acta 2006, 1757(5-6):639-647.

10. Green DR, Kroemer G: The pathophysiology of mitochondrial cell death. Science 2004, 305(5684):626-629.

11. Lemasters JJ, Qian T, He L, Kim JS, Elmore SP, Cascio WE, Brenner DA: Role of mitochondrial inner membrane permeabilization in necrotic cell death, apoptosis, and autophagy. Antioxid Redox Signal 2002, 4(5):769-781.

12. Mattson MP, Kroemer G: Mitochondria in cell death: novel targets for neuroprotection and cardioprotection. Trends $\mathrm{Mol}$ Med 2003, 9(5):196-205.

13. Scorrano L, Korsmeyer SJ: Mechanisms of cytochrome c release by proapoptotic BCL-2 family members. Biochem Biophys Res Commun 2003, 304(3):437-444.

14. Jiang J, Huang Z, Zhao Q, Feng W, Belikova NA, Kagan VE: Interplay between bax, reactive oxygen species production, and cardiolipin oxidation during apoptosis. Biochem Biophys Res Commun 2008, 368:145-150.

15. Kirkland RA, Franklin JL: Evidence for redox regulation of cytochrome $\mathrm{C}$ release during programmed neuronal death: antioxidant effects of protein synthesis and caspase inhibition. J Neurosci 2001, 21(6):1949-1963.

16. Kirkland RA, Windelborn JA, Kasprzak JM, Franklin JL: A Baxinduced pro-oxidant state is critical for cytochrome c release during programmed neuronal death. J Neurosci 2002, 22(15): 6480-6490.

17. Harris $\mathrm{MH}$, Thompson $\mathrm{CB}$ : The role of the Bcl-2 family in the regulation of outer mitochondrial membrane permeability. Cell Death Differ 2000, 7(12):1182-1191.

18. Scaffidi C, Fulda S, Srinivasan A, Friesen C, Li F, Tomaselli KJ, Debatin KM, Krammer PH, Peter ME: Two CD95 (APO-1/Fas) signaling pathways. Embo J 1998, 17(6):1675-1687.

19. Enns GM: The contribution of mitochondria to common disorders. Mol Genet Metab 2003, 80(1-2):11-26.

20. Han YY, Reynolds IJ: Mitochondria in Acute Brain Injury. Brain Injury (eds Clark RSB and Kochanek PM), Kluwer Academic Publishing 2001:145-161.

21. Bohnensack R, Kuster $U$, Letko G: Rate-controlling steps of oxidative phosphorylation in rat liver mitochondria. A synoptic approach of model and experiment. Biochim Biophys Acta 1982, 680(3):271-280.

22. Brawand F, Folly G, Walter P: Relation between extra- and intramitochondrial ATP/ADP ratios in rat liver mitochondria. Biochim Biophys Acta 1980, 590(3):285-289.

23. Davis EJ, Lumeng L, Bottoms D: On the relationships between the stoichiometry of oxidative phosphorylation and the phosphorylation potential of rat liver mitochondria as functions of respiratory state. FEBS Lett 1974, 39(1):9-12.

24. Kholodenko B, Zilinskiene V, Borutaite V, Ivanoviene L, Toleikis A, Praskevicius $A$ : The role of adenine nucleotide translocators in regulation of oxidative phosphorylation in heart mitochondria. FEBS Lett 1987, 223(2):247-250.

25. Tager JM, Wanders RJ, Groen AK, Kunz W, Bohnensack R, Kuster U, Letko G, Bohme G, Duszynski J, Wojtczak L: Control of mitochondrial respiration. FEBS Lett 1983, 151(1):1-9.

26. Hirabara SM, Silveira LR, Abdulkader FR, Alberici LC, Procopio J, Carvalho CR, Pithon-Curi TC, Curi R: Role of fatty acids in the transition from anaerobic to aerobic metabolism in skeletal muscle during exercise. Cell Biochem Funct 2006, 24(6):475481.

27. Chen Q, Chai YC, Mazumder S, Jiang C, Macklis RM, Chisolm
GM, Almasan A: The late increase in intracellular free radical oxygen species during apoptosis is associated with cytochrome c release, caspase activation, and mitochondrial dysfunction. Cell Death Differ 2003, 10(3):323-334.

28. Riedl SJ, Salvesen GS: The apoptosome: signalling platform of cell death. Nat Rev Mol Cell Biol 2007.

29. Protti A, Singer M: Bench-to-bedside review: potential strategies to protect or reverse mitochondrial dysfunction in sepsis-induced organ failure. Crit Care 2006, 10(5):228.

30. Robertson CL: Mitochondrial dysfunction contributes to cell death following traumatic brain injury in adult and immature animals. J Bioenerg Biomembr 2004, 36(4):363-368.

31. Sullivan PG, Springer JE, Hall ED, Scheff SW: Mitochondrial uncoupling as a therapeutic target following neuronal injury. $J$ Bioenerg Biomembr 2004, 36(4):353-356.

32. Brealey D, Brand M, Hargreaves I, Heales S, Land J, Smolenski R, Davies NA, Cooper CE, Singer M: Association between mitochondrial dysfunction and severity and outcome of septic shock. Lancet 2002, 360(9328):219-223.

33. Gasparetto A, Corbucci GG, Candiani A, Gohil K, Edwards RH: Effect of tissue hypoxia and septic shock on human skeletal muscle mitochondria. Lancet 1983, 2(8365-66):1486.

34. Llesuy S, Evelson P, Gonzalez-Flecha B, Peralta J, Carreras MC, Poderoso JJ, Boveris A: Oxidative stress in muscle and liver of rats with septic syndrome. Free Radic Biol Med 1994, 16(4): 445-451.

35. Nisoli E, Clementi E, Paolucci C, Cozzi V, Tonello C, Sciorati C, Bracale R, Valerio A, Francolini M, Moncada S et al: Mitochondrial biogenesis in mammals: the role of endogenous nitric oxide. Science 2003, 299(5608):896-899.

36. Verweij BH, Muizelaar JP, Vinas FC, Peterson PL, Xiong Y, Lee $\mathrm{CP}$ : Mitochondrial dysfunction after experimental and human brain injury and its possible reversal with a selective $\mathrm{N}$-type calcium channel antagonist (SNX-111). Neurol Res 1997, 19(3):334-339.

37. Okonkwo DO, Povlishock JT: An intrathecal bolus of cyclosporin A before injury preserves mitochondrial integrity and attenuates axonal disruption in traumatic brain injury. $J$ Cereb Blood Flow Metab 1999, 19(4):443-451.

38. Sullivan PG, Thompson MB, Scheff SW: Cyclosporin A attenuates acute mitochondrial dysfunction following traumatic brain injury. Exp Neurol 1999, 160(1):226-234.

39. Xiong Y, Gu Q, Peterson PL, Muizelaar JP, Lee CP: Mitochondrial dysfunction and calcium perturbation induced by traumatic brain injury. J Neurotrauma 1997, 14(1):23-34.

40. Singh IN, Sullivan PG, Deng Y, Mbye LH, Hall ED: Time course of post-traumatic mitochondrial oxidative damage and dysfunction in a mouse model of focal traumatic brain injury: implications for neuroprotective therapy. J Cereb Blood Flow Metab 2006, 26(11):1407-1418.

41. Bayir $H$, Tyurin VA, Tyurina YY, Viner R, Ritov V, Amoscato AA, Zhao Q, Zhang XJ, Janesko-Feldman KL, Alexander $\mathrm{H}$ et al: Selective early cardiolipin peroxidation after traumatic brain injury: an oxidative lipidomics analysis. Ann Neurol 2007, 62(2):154-169.

42. Murphy MP, Smith RA: Targeting antioxidants to mitochondria by conjugation to lipophilic cations. Annu Rev Pharmacol Toxicol 2007, 47:629-656.

43. Alessandri B, Rice AC, Levasseur J, DeFord M, Hamm RJ, Bullock MR: Cyclosporin A improves brain tissue oxygen consumption and learning/memory performance after lateral fluid percussion injury in rats. $J$ Neurotrauma 2002, 19(7):829-841.

44. Scheff SW, Sullivan PG: Cyclosporin A significantly ameliorates cortical damage following experimental traumatic brain injury in rodents. J Neurotrauma 1999, 16(9):783-792.

45. Mazzeo AT, Kunene NK, Gilman CB, Hamm RJ, Hafez N, Bullock MR: Severe human traumatic brain injury, but not cyclosporin a treatment, depresses activated $\mathrm{T}$ lymphocytes early after injury. J Neurotrauma 2006, 23(6):962-975.

46. Droge $\mathrm{W}$ : Free radicals in the physiological control of cell function. Physiol Rev 2002, 82(1):47-95.

47. Gorbunov NV, Elsayed NM, Kisin ER, Kozlov AV, Kagan VE: Air blast-induced pulmonary oxidative stress: interplay among hemoglobin, antioxidants, and lipid peroxidation. Am J Physiol 1997, 272(2 Pt 1):L320-334.

48. Turrens JF: Mitochondrial formation of reactive oxygen species. J Physio/ 2003, 552(Pt 2):335-344. 
49. Barja G: Mitochondrial oxygen radical generation and leak: sites of production in states 4 and 3 , organ specificity, and relation to aging and longevity. J Bioenerg Biomembr 1999, 31(4):347-366.

50. Turrens JF, Boveris A: Generation of superoxide anion by the NADH dehydrogenase of bovine heart mitochondria. Biochem $J$ 1980, $191(2): 421-427$.

51. Adam-Vizi V: Production of reactive oxygen species in brain mitochondria: contribution by electron transport chain and non-electron transport chain sources. Antioxid Redox Signal 2005, 7(9-10):1140-1149.

52. Babior BM: The leukocyte NADPH oxidase. Isr Med Assoc J 2002, 4(11):1023-1024.

53. Yokoyama Y, Beckman JS, Beckman TK, Wheat JK, Cash TG, Freeman BA, Parks DA: Circulating xanthine oxidase: potential mediator of ischemic injury. Am J Physiol 1990, 258(4 Pt 1): G564-570.

54. Goeptar AR, te Koppele JM, van Maanen JM, Zoetemelk CE, Vermeulen NP: One-electron reductive bioactivation of 2,3,5,6tetramethylbenzoquinone by cytochrome P450. Biochem Pharmacol 1992, 43(2):343-352.

55. McCord JM, Fridovich I: The utility of superoxide dismutase in studying free radical reactions. I. Radicals generated by the interaction of sulfite, dimethyl sulfoxide, and oxygen. $J$ Biol Chem 1969, 244(22):6056-6063.

56. Rhee SG, Yang KS, Kang SW, Woo HA, Chang TS: Controlled elimination of intracellular $\mathrm{H}(2) \mathrm{O}(2)$ : regulation of peroxiredoxin, catalase, and glutathione peroxidase via post-translational modification. Antioxid Redox Signal 2005, 7(5-6): 619-626.

57. Ghafourifar P, Richter C: Nitric oxide synthase activity in mitochondria. FEBS Lett 1997, 418(3):291-296.

58. Giulivi C: Functional implications of nitric oxide produced by mitochondria in mitochondrial metabolism. Biochem J 1998, 332 (Pt 3):673-679.

59. Poderoso JJ, Carreras MC, Lisdero C, Riobo N, Schopfer F, Boveris A: Nitric oxide inhibits electron transfer and increases superoxide radical production in rat heart mitochondria and submitochondrial particles. Arch Biochem Biophys 1996, 328(1):85-92.

60. Radi R, Beckman JS, Bush KM, Freeman BA: Peroxynitriteinduced membrane lipid peroxidation: the cytotoxic potential of superoxide and nitric oxide. Arch Biochem Biophys 1991, 288(2):481-487.

61. Radi R, Cassina A, Hodara R: Nitric oxide and peroxynitrite interactions with mitochondria. Biol Chem 2002, 383(3-4):401409.

62. Kagan VE, Tyurin VA, Jiang J, Tyurina YY, Ritov VB, Amoscato AA, Osipov AN, Belikova NA, Kapralov AA, Kini V et al: Cytochrome c acts as a cardiolipin oxygenase required for release of proapoptotic factors. Nat Chem Biol 2005, 1(4):223-232.

63. Macias CA, Chiao JW, Xiao J, Arora DS, Tyurina YY, Delude RL, Wipf $P$, Kagan VE, Fink MP: Treatment with a novel hemigramicidin-TEMPO conjugate prolongs survival in a rat model of lethal hemorrhagic shock. Ann Surg 2007, 245(2):305-314.

64. Basova LV, Kurnikov IV, Wang L, Ritov VB, Belikova NA, Vlasova, II, Pacheco AA, Winnica DE, Peterson J, Bayir $\mathrm{H}$ et al: Cardiolipin Switch in Mitochondria: Shutting off the Reduction of Cytochrome $c$ and Turning on the Peroxidase Activity. Biochemistry 2007, 46(11):3423-3434.

65. Belikova NA, Vladimirov YA, Osipov AN, Kapralov AA, Tyurin VA, Potapovich MV, Basova LV, Peterson J, Kurnikov IV, Kagan VE: Peroxidase activity and structural transitions of cytochrome $c$ bound to cardiolipin-containing membranes. Biochemistry 2006, 45(15):4998-5009.

66. Kapralov AA, Kurnikov IV, Vlasova, II, Belikova NA, Tyurin VA, Basova LV, Zhao Q, Tyurina YY, Jiang J, Bayir $\mathrm{H}$ et al: The hierarchy of structural transitions induced in cytochrome $c$ by anionic phospholipids determines its peroxidase activation and selective peroxidation during apoptosis in cells. Biochemistry 2007, 46(49):14232-14244.

67. Petrosillo G, Casanova G, Matera M, Ruggiero FM, Paradies G: Interaction of peroxidized cardiolipin with rat-heart mitochondrial membranes: Induction of permeability transition and cytochrome c release. FEBS Lett 2006.

68. Nomura K, Imai H, Koumura T, Kobayashi T, Nakagawa Y: Mitochondrial phospholipid hydroperoxide glutathione peroxidase inhibits the release of cytochrome $\mathrm{c}$ from mitochondria by suppressing the peroxidation of cardiolipin in hypoglycaemiainduced apoptosis. Biochem J 2000, 351 (Pt 1):183-193.

69. Ran $\mathrm{Q}$, Liang $\mathrm{H}$, Gu M, Qi W, Walter CA, Roberts L, 2nd, Herman B, Richardson A, Van Remmen H: Transgenic mice overexpressing glutathione peroxidase 4 are protected against oxidative stress-induced apoptosis. J Biol Chem 2004, 279(53):55137-55146.

70. Hotchkiss RS, Coopersmith CM, Karl IE: Prevention of lymphocyte apoptosis-a potential treatment of sepsis? Clin Infect Dis 2005, 41 Suppl 7:S465-469.

71. Borisenko GG, Martin I, Zhao Q, Amoscato AA, Kagan VE: Nitroxides scavenge myeloperoxidase-catalyzed thiyl radicals in model systems and in cells. J Am Chem Soc 2004, 126(30): 9221-9232.

72. Zhang R, Goldstein S, Samuni A: Kinetics of superoxideinduced exchange among nitroxide antioxidants and their oxidized and reduced forms. Free Radic Biol Med 1999, 26(9-10): 1245-1252.

73. Krishna MC, Grahame DA, Samuni A, Mitchell JB, Russo A: Oxoammonium cation intermediate in the nitroxide-catalyzed dismutation of superoxide. Proc Natl Acad Sci U S A 1992, 89(12):5537-5541.

74. Samuni A, Krishna CM, Riesz P, Finkelstein E, Russo A: A novel metal-free low molecular weight superoxide dismutase mimic. J Biol Chem 1988, 263(34):17921-17924.

75. Hahn SM, Wilson L, Krishna CM, Liebmann J, DeGraff W, Gamson J, Samuni A, Venzon D, Mitchell JB: Identification of nitroxide radioprotectors. Radiat Res 1992, 132(1):87-93.

76. Howard BJ, Yatin S, Hensley K, Allen KL, Kelly JP, Carney J, Butterfield DA: Prevention of hyperoxia-induced alterations in synaptosomal membrane-associated proteins by N-tert-butylalpha-phenylnitrone and 4-hydroxy-2,2,6,6-tetramethylpiperidin1-oxyl (Tempol). J Neurochem 1996, 67(5):2045-2050.

77. Karmeli F, Eliakim R, Okon E, Samuni A, Rachmilewitz D: A stable nitroxide radical effectively decreases mucosal damage in experimental colitis. Gut 1995, 37(3):386-393.

78. McDonald MC, Zacharowski K, Bowes J, Cuzzocrea S, Thiemermann C: Tempol reduces infarct size in rodent models of regional myocardial ischemia and reperfusion. Free Radic Biol Med 1999, 27(5-6):493-503.

79. Trembovler V, Beit-Yannai E, Younis F, Gallily R, Horowitz M Shohami E: Antioxidants attenuate acute toxicity of tumor necrosis factor-alpha induced by brain injury in rat. $J$ Interferon Cytokine Res 1999, 19(7):791-795.

80. Gariboldi MB, Ravizza R, Petterino C, Castagnaro M, Finocchiaro G, Monti E: Study of in vitro and in vivo effects of the piperidine nitroxide Tempol-a potential new therapeutic agent for gliomas. Eur J Cancer 2003, 39(6):829-837.

81. Dessolin J, Schuler M, Quinart A, De Giorgi F, Ghosez L, Ichas F: Selective targeting of synthetic antioxidants to mitochondria: towards a mitochondrial medicine for neurodegenerative diseases? Eur J Pharmacol 2002, 447(2-3):155-161.

82. Dhanasekaran A, Kotamraju S, Karunakaran C, Kalivendi SV, Thomas S, Joseph J, Kalyanaraman B: Mitochondria superoxide dismutase mimetic inhibits peroxide-induced oxidative damage and apoptosis: role of mitochondrial superoxide. Free Radic Biol Med 2005, 39(5):567-583.

83. Jiang J, Kurnikov I, Belikova NA, Xiao J, Zhao Q, Amoscato AA, Braslau R, Studer A, Fink MP, Greenberger JS et al: Structural requirements for optimized delivery, inhibition of oxidative stress, and antiapoptotic activity of targeted nitroxides. J Pharmacol Exp Ther 2007, 320(3):1050-1060.

84. Wipf $P$, Xiao J, Jiang J, Belikova NA, Tyurin VA, Fink MP, Kagan VE: Mitochondrial targeting of selective electron scavengers: synthesis and biological analysis of hemigramicidin-TEMPO conjugates. J Am Chem Soc 2005, 127(36):12460-12461.

85. Ayala A, Chung CS, Lomas JL, Song GY, Doughty LA, Gregory $\mathrm{SH}$, Cioffi WG, LeBlanc BW, Reichner J, Simms $\mathrm{HH}$ et al: Shock-induced neutrophil mediated priming for acute lung injury in mice: divergent effects of TLR-4 and TLR-4/FasL deficiency. Am J Pathol 2002, 161(6):2283-2294.

86. Sheehan M, Wong HR, Hake PW, Malhotra V, O'Connor M, Zingarelli B: Parthenolide, an inhibitor of the nuclear factorkappaB pathway, ameliorates cardiovascular derangement and outcome in endotoxic shock in rodents. Mol Pharmacol 2002, 61(5):953-963. 
87. Fadeel B, Kagan VE: Apoptosis and macrophage clearance of neutrophils: regulation by reactive oxygen species. Redox Rep 2003, 8(3):143-150.

88. Savill JS, Wyllie AH, Henson JE, Walport MJ, Henson PM, Haslett C: Macrophage phagocytosis of aging neutrophils in inflammation. Programmed cell death in the neutrophil leads to its recognition by macrophages. J Clin Invest 1989, 83(3):865875.

89. Maianski NA, Geissler J, Srinivasula SM, Alnemri ES, Roos D, Kuijpers TW: Functional characterization of mitochondria in neutrophils: a role restricted to apoptosis. Cell Death Differ 2004, 11(2):143-153.

90. van Raam BJ, Verhoeven AJ, Kuijpers TW: Mitochondria in neutrophil apoptosis. Int J Hematol 2006, 84(3):199-204.

91. Borregaard N, Herlin T: Energy metabolism of human neutrophils during phagocytosis. J Clin Invest 1982, 70(3):550557.

92. Morimoto K, Janssen WJ, Fessler MB, McPhillips KA, Borges VM, Bowler RP, Xiao YQ, Kench JA, Henson PM, Vandivier RW: Lovastatin enhances clearance of apoptotic cells (efferocytosis) with implications for chronic obstructive pulmonary disease. J Immuno/ 2006, 176(12):7657-7665.

93. Vandivier RW, Henson PM, Douglas IS: Burying the dead: the impact of failed apoptotic cell removal (efferocytosis) on chronic inflammatory lung disease. Chest 2006, 129(6):16731682.

94. Fadok VA, Bratton DL, Frasch SC, Warner ML, Henson PM: The role of phosphatidylserine in recognition of apoptotic cells by phagocytes. Cell Death Differ 1998, 5(7):551-562.

95. Gardai SJ, Bratton DL, Ogden CA, Henson PM: Recognition ligands on apoptotic cells: a perspective. J Leukoc Biol 2006, 79(5):896-903.

96. Huynh ML, Fadok VA, Henson PM: Phosphatidylserine-dependent ingestion of apoptotic cells promotes TGF-beta1 secretion and the resolution of inflammation. J Clin Invest 2002, 109(1):41-50.

97. Sanford AN, Suriano AR, Herche D, Dietzmann K, Sullivan KE: Abnormal apoptosis in chronic granulomatous disease and autoantibody production characteristic of lupus. Rheumatology (Oxford) 2006, 45(2):178-181.

98. Daleke DL: Regulation of transbilayer plasma membrane phospholipid asymmetry. J Lipid Res 2003, 44(2):233-242.

99. Arroyo A, Modriansky M, Serinkan FB, Bello RI, Matsura T, Jiang J, Tyurin VA, Tyurina YY, Fadeel B, Kagan VE: NADPH oxidasedependent oxidation and externalization of phosphatidylserine during apoptosis in Me2SO-differentiated HL-60 cells. Role in phagocytic clearance. J Biol Chem 2002, 277(51): 49965-49975.

100. Tyurina YY, Basova LV, Konduru NV, Tyurin VA, Potapovich Al, Cai P, Bayir H, Stoyanovsky D, Pitt BR, Shvedova AA et al: Nitrosative stress inhibits the aminophospholipid translocase resulting in phosphatidylserine externalization and macrophage engulfment: implications for the resolution of inflammation. J Biol Chem 2007, 282(11):8498-8509.

101. Kagan VE, Bayir H, Shvedova AA: Nanomedicine and nanotoxicology: two sides of the same coin. Nanomedicine 2005, 1(4): 313-316.

102. Cai D, Mataraza JM, Qin ZH, Huang Z, Huang J, Chiles TC, Carnahan D, Kempa K, Ren Z: Highly efficient molecular delivery into mammalian cells using carbon nanotube spearing. Nat Methods 2005, 2(6):449-454.

103. Kam NW, O'Connell M, Wisdom JA, Dai H: Carbon nanotubes as multifunctional biological transporters and near-infrared agents for selective cancer cell destruction. Proc Natl Acad Sci U S A 2005, 102(33):11600-11605. 